\title{
SURGICAL MANAGEMENT OF EVENTRATION OF DIAPHRAGM- A RARE CASE
}

\author{
Disha Syal ${ }^{1}$
}

1M. S. (General Surgery), DNB (GI Surgery), FIAGES (Colorectal Surgery).

\begin{tabular}{l}
\hline ABSTRACT \\
BACKGROUND \\
A 32-year-old man presented with recurrent episodes of vomiting and breathing difficulty and had unrecordable blood pressure. \\
On examination, he was found to have decreased air entry on left side and CECT suggested eventration of diaphragm. He \\
underwent laparotomy and plication of diaphragm after resuscitation and recovered well.
\end{tabular}

\section{KEYWORDS}

Eventration, Diaphragm, Surgical Management.

HOW TO CITE THIS ARTICLE: Syal D. Surgical management of eventration of diaphragm- a rare case. J. Evolution Med. Dent. Sci. 2017;6(36):2982-2983, DOI: 10.14260/Jemds/2017/642

\section{BACKGROUND}

Eventration of diaphragm is a rare entity and is more commonly seen in infants and children when they present with severe respiratory distress. It requires emergency surgery and asymptomatic cases require no treatment. However, adult patients can present with breathing difficulty and obstruction and symptomatic patients require surgery. We present a similar case, which was successfully managed with surgical intervention.

\section{CASE REPORT}

A 32 years old male presented to casualty with multiple episodes of vomiting and breathing difficulty and uneasiness in chest. He had unrecordable blood pressure with tachycardia of $136 / \mathrm{min}$. He also had history of cough and low-grade fever for last 5 days, for which he was taking some medication. He had an unremarkable past medical history with no history of trauma. There was decreased air entry on left side of chest with intestinal gurgling.

He was resuscitated and nasogastric tube was inserted. On evaluation, he had high total leucocyte count of 26,000 and postero-anterior chest radiograph showed elevated left hemidiaphragm with mediastinal shift to right. His Computerised Tomography of the chest and abdomen showed a thinned out left hemidiaphragm and compression of left thorax by upward displacement of abdominal viscera including spleen, small bowel and left kidney with mediastinal shift to right. (Fig.1 \& 2)

After administration of intravenous antibiotics and normalisation of counts he was operated and on laparotomy found to have omentum, small bowel adherent to left diaphragm (Fig. 3). The abdominal contents were brought down after adhesiolysis and diaphragm was plicated using multiple interrupted sutures of No. 1 Prolene (Fig. 4) placed in antero-posterior direction. Left tube thoracostomy was performed using 28-Fr chest tube. He recovered well and was

Financial or Other, Competing Interest: None.

Submission 31-01-2017, Peer Review 22-04-2017,

Acceptance 27-04-2017, Published 04-05-2017.

Corresponding Author:

Dr. Disha Syal,

\#146, Phase 2, Urban Estate,

Jalandhar-144022, Punjab.

E-mail: dishasood@yahoo.com drdishasyal@gmail.com

DOI: $10.14260 /$ jemds $/ 2017 / 642$

\section{(c) $($ ) $\$$}

discharged on $8^{\text {th }}$ post-operative day. The post-operative chest x-ray showed left hemidiaphragm nearly at the same level as the right hemidiaphragm.

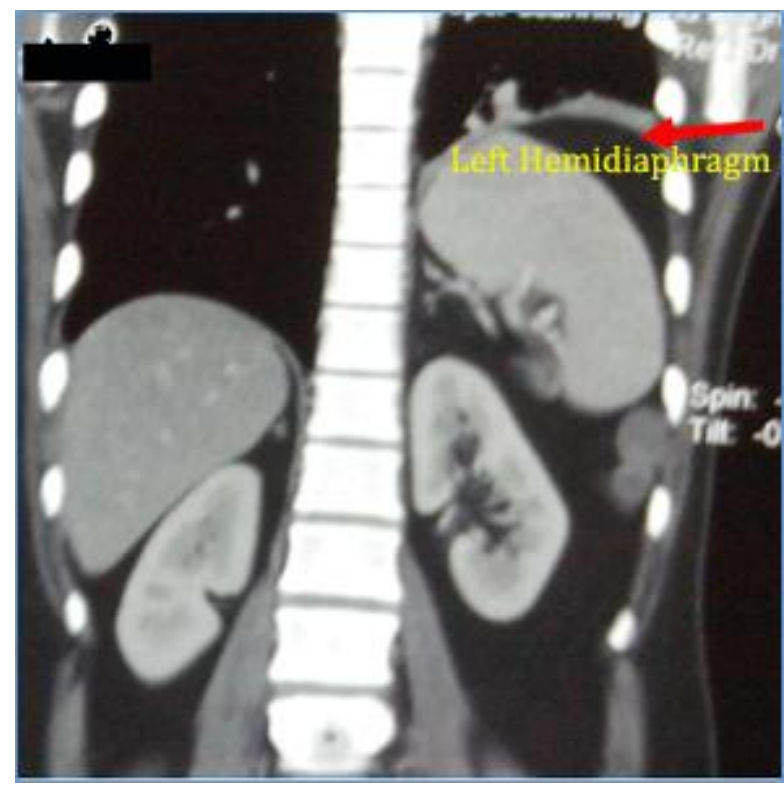

Figure 1. CECT Scan of the Chest and Abdomen showing Elevated Left Hemidiaphragm

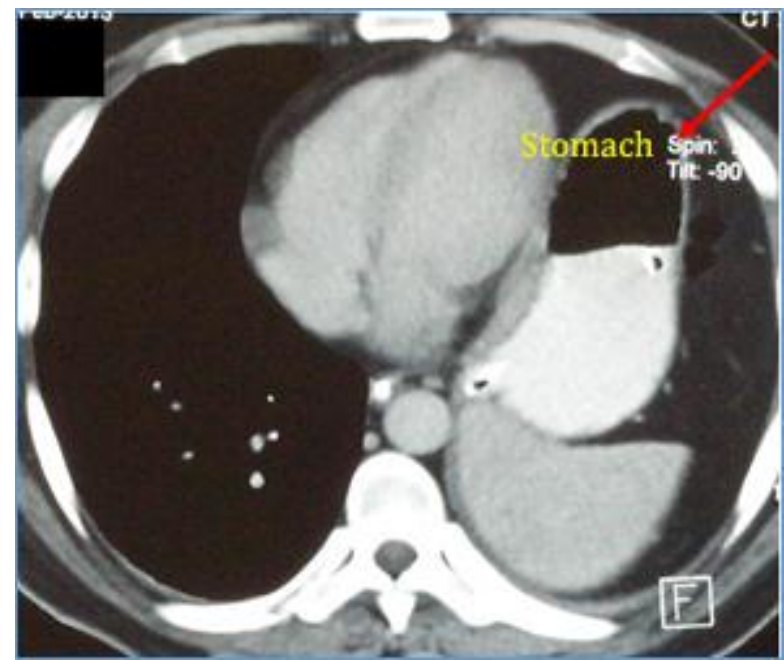

Figure 2. CECT of Chest showing Spleen and Stomach Pushed superiorly in Thorax compressing the Left Lung 


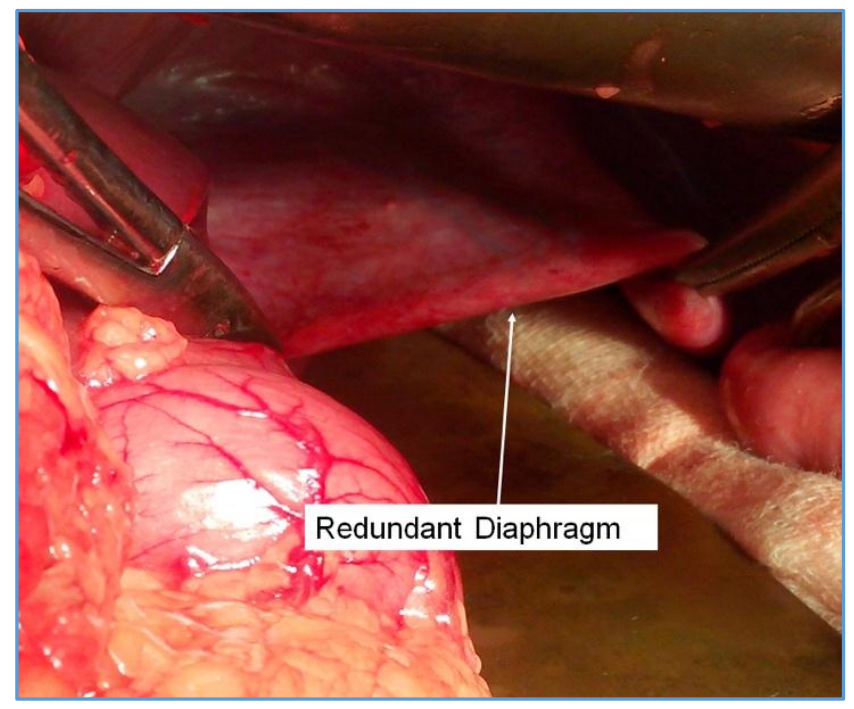

Figure 3. Operative Photograph showing Redundant Left Hemidiaphragm

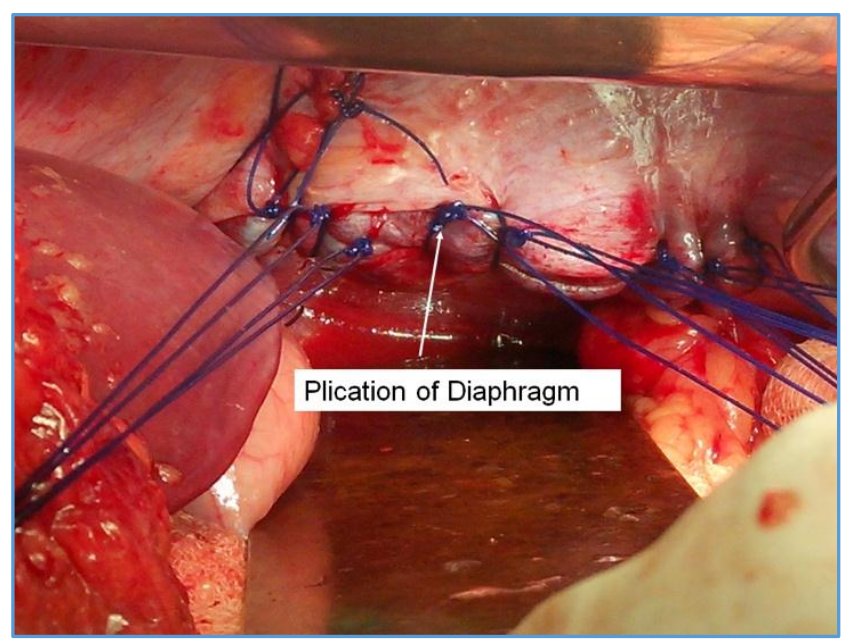

Figure 4. Operative Photograph showing Plicated Left Hemidiaphragm

\section{DISCUSSION}

Eventration of diaphragm is defined as a condition in which the diaphragm ascends abnormally high into the chest. It may be congenital, i.e. present since birth or acquired when it develops later in life due to some pathology. Congenital eventration is considered as a true eventration, as there is a defect in development of central part of diaphragm. [1] They present early in life and with severe respiratory distress and require immediate intervention, whereas acquired condition can be due to various factors like polio, herpes zoster, diphtheria or influenza[2] or malignancy and autoimmune disorders, which affect the diaphragm or phrenic nerve. There occurs atrophy of muscle secondary to which there is relaxation and displacement of diaphragm by abdominal viscera. Eventration is more commonly seen on the left side and seen more commonly in men.[3]

Eventration of diaphragm in an asymptomatic patient requires no treatment and requires chest physiotherapy and measures to reduce weight. However, those who present with cough, breathing difficulty, vomiting or impairment of daily activities require surgical intervention.

Various approaches for surgical repair include abdominal, where it is easier to manage the abdominal viscera and the other is thoracic approach where thoracic structures can also be inspected. Nowadays video assisted thoracoscopic surgery is also available, where various surgical modalities depend on the thickness of diaphragm and if it is thinned out then it requires plication or double breasting along with reinforcement using mesh. If the thickness is good, then plication is sufficient to attain desired tension as was performed in our patient.

\section{REFERENCES}

[1] Shields TW. Diaphragmatic function, diaphragmatic paralysis, and eventration of the diaphragm. $6^{\text {th }}$ edn. In: Shields TW, Lo Cicero J, Ponn R, et al. General thoracic surgery. Phladelphia: Lippinncott Williams \& Wilkins 2005:740-5.

[2] Frechette E, Cloutier R, Deslauriers J. Cgenital eventration and acuired elevation of the diaphragm. $2^{\text {nd }}$ edn. In: Pearson FG, Cooper JD, Deslauriers J, et al. (eds). Thoracic Surgery. Philadelphia: Churchill Livingstone 2002:1537-49.

[3] Reed JA, Borden DL. Eventration of the diaphragm. Arch Surg 1935;31(1):30-64. 